\title{
A Decision-Making Framework for the Optimal Selection of Suppliers
}

\author{
C. Keramydas ${ }^{1 *}$, A. Xanthopoulos ${ }^{2}$, D. Aidonis ${ }^{3}$ \\ 1,2Department of Mechanical Engineering, Aristotle University of Thessaloniki, Greece \\ ${ }^{3}$ Department of Logistics, Alexander Technological Educational Institute of Thessaloniki, Branch of Katerini, Greece \\ ${ }^{1}$ chkeramy@auth.gr, 2axanthop@auth.gr, 32daidonis@auth.gr
}

\begin{abstract}
As supply chains continue to globalize, the need for robust supplier qualification and supplier selection and evaluation programs becomes increasingly critical. In this context, this paper aims to present a methodological approach for the optimization of the procurement processes in today's globalized supply chains. More specifically, we first provide a categorization of the relevant past research efforts, and then propose a generic methodological framework for the supplier selection and supplier evaluation problem. This framework is constituted by a five phased conceptual decision-making methodology that outlines the whole life cycle of the supplier selection and evaluation processes. In addition, we provide a new analytical goal-programming model for the initial selection and the periodic re-evaluation of suppliers in today's globalized environment. This mathematical programming model is based on newly developed and integrated real world supplier quality indices.
\end{abstract}

Keywords: supplier selection and (re-)evaluation processes, methodological framework, optimization, goalprogramming.

\section{Introduction}

An effective purchasing and supply management policy entails purchase of the right product, at the right price, in the right quality and quantity, at the right time and on a continuing base. Today, there are constant pressures to suppliers to keep on decreasing the length of time between placing an order and its due date, underscoring the need for systemic and efficient satisfaction of the customer orders. Customers often expect same day service and even when they are willing to wait they expect to be quoted with accurate delivery lead times. In addition, the number of product offerings has increased, while at the same time the life cycle of the products is constantly decreasing. On the other hand, customers often recognize that their procurement policies are inefficient, exhibiting long cycle times, large lot sizes, low yield and long and unpredictable lead times.
Further, taking into consideration the ever increasing globalization of logistics networks, the need for collaboration with reliable and quality certified suppliers and the use of sophisticated supplier selection and evaluation management systems become continuously more critical.

In this context, this paper aims to present a holistic methodological approach for the optimization of the procurement processes in today's globalized supply chains. Specifically, we first provide a categorization of the relevant past research efforts in order to present the managerial insights that result from the existing literature, and to highlight the contribution of this work by considering the current state of knowledge. Secondly, we propose a generic methodological framework for the supplier selection and evaluation problem. This framework is constituted by a five-phased conceptual decision-

${ }^{*}$ Corresponding Author 
making methodology that outlines the whole life cycle of the supplier selection and evaluation processes.

Next, we provide a new generalized goalprogramming model for the initial selection and the periodic re-evaluation of suppliers. The number of suppliers to be used may be predefined or not, while the proposed optimization model may also consider the cases of nearshore and offshore suppliers, as well as emergent ones. Furthermore, this quantitative model is based on newly-developed real-world supplier quality indices.

The rest of the paper is organized as follows. In Section 2 we present a literature review and a categorization of the past modeling approaches dealing with the supplier selection problem. Section 3 accommodates the proposed methodological framework, while in Section 4 we present the proposed optimization model, for supporting the relevant decision-making processes. Finally, we provide conclusions and directions for future research.

\section{Related Work}

The critical role of the supplier selection process in the development of an organization and the effects on its profitability and viability has been detected and recognized since early 1940s (Lewis, 1943). Then Dickson (1966) conducted a survey among purchasing agents and managers in the U.S.A. and Canada that revealed the existence of 23 criteria that mainly affect the supplier selection decision-making process. Moreover, Hakansson and Wootz (1975) and Dempsey (1978) added some new complementary factors/criteria to those that had already been proposed by Dickson (1966), further enhancing the perception that the quality of products and their delivery are two critical factors for the supplier selection process.

The relevant literature regarding the supplier selection problem, during the last sixty years, is spread over the following two basic directions: the identification and selection of the criteria that a purchasing officer should take into account, and the methods that should be employed in order to compare, evaluate and rank suppliers or to detect the optimal one.

Four review papers have been already published for the supplier selection and evaluation problem. To this effect, the first effort was that of Webber et al. (1991) who reviewed and classified the different methods/approaches that had been employed to address the vendor selection problem across different business environments. Later on, Degraeve et al. (2000) presented a new taxonomy of the relevant research works based on a single/ multiple item and with/without inventory management considerations categorization, and compared the relative efficiency of the vendor selection models using the concept of total cost of ownership (i.e. an approach of quantifying all the costs associated with the purchase process throughout the entire value chain of an organization). De Boer et al. (2000) extended these works by considering the diversity of the procurement situations (in terms of complexity and importance), while they have taken into account all the phases in the supplier selection process. In the most recent literature review, Ho et al. (2010) presented a categorization of the multi-criteria decision-making approaches for the supplier evaluation and selection processes, and provided also evidence that the multicriteria decision-making models are better than the traditional cost-based ones.

In this manuscript, the most relevant, to our work, research papers found in the literature are classified into two main categories (Table 1), namely:

- Qualitative approaches.

- Quantitative approaches: Non-optimization and optimization models.

\subsection{Qualitative Approaches}

In general, qualitative papers address the following aspects of the supplier selection problem: identification of suppliers, evaluation of suppliers, negotiations with suppliers, strategic partnerships, etc.

Spekman (1988) intended to help managers understand the nature of strategic partnerships and to better appreciate the decision criteria that will lead to the selection of good partners. Masella and Rangone (2000) compared four different vendor selection systems, which depend on the time-frame (short-term versus long term) and on the content (logistics versus strategic) of the co-operative customer/supplier relationships, by considering various sets of measures. Then Pidduck (2006) presented a partner negotiation model for the 
Table 1. Taxonomy of the past research papers

\begin{tabular}{|c|c|}
\hline Methodology & Papers \\
\hline Analytic hierarchy process & $\begin{array}{l}\text { Celebi \& Bayraktar (2008); Chen \& } \\
\text { Huang (2007); Ghoudsypour \& O'Brien } \\
\text { (1998); Morlacchi et al. (1997); Nydick } \\
\text { \& Hill (1992) }\end{array}$ \\
\hline Case-based reasoning & Cook (1997) \\
\hline Chance constrained-programming & Wu \& Olson (2008) \\
\hline Cluster analysis & Hinkle et al. (1969) \\
\hline Conceptual framework & $\begin{array}{l}\text { Beil (2010); Masella \& Rangone (2000); } \\
\text { Pidduck (2006); Spekman (1988) }\end{array}$ \\
\hline Conjoint Analysis & Mummalaneni et al. (1996) \\
\hline Data envelopment analysis & $\begin{array}{l}\text { Liu et al. (2000); Weber \& Desai (1996); } \\
\text { Wu \& Olson (2008) }\end{array}$ \\
\hline Discriminant Analysis & Temur et al. (2009) \\
\hline Expert systems & $\begin{array}{l}\text { Jalao \& Martinez (2009); Vokurka et al. } \\
\text { (1996) }\end{array}$ \\
\hline Fuzzy set theory & $\begin{array}{l}\text { Morlacchi et al. (1997); Kumar et al. } \\
\text { (2004) }\end{array}$ \\
\hline Goal-programming & Karpak et al. (1999); Kumar et al. (2004) \\
\hline Intelligent Software Agent & Khoo et al. (1998) \\
\hline Linear-programming & Ghoudsypour \& O'Brien (1998) \\
\hline Market research & Goffin et al. (1997) \\
\hline Mixed integer-programming & $\begin{array}{l}\text { Chaudhry et al. (1993); Rosenthal et al. } \\
\text { (1995) }\end{array}$ \\
\hline Multi-objective programming & $\begin{array}{l}\text { Amid et al. (2006); Weber \& Current } \\
\text { (1993); Wu \& Olson (2008) }\end{array}$ \\
\hline Multiple regression analysis & Chapman \& Carter (1990) \\
\hline Neural network & $\begin{array}{l}\text { Celebi \& Bayraktar (2008); Temur et al. } \\
\text { (2009) }\end{array}$ \\
\hline Principal Component Analysis & Petroni \& Braglia (2000) \\
\hline Simulation & Ding et al. (2006) \\
\hline Total cost of ownership & Degraeve et al. (2000); Ellram (1995) \\
\hline
\end{tabular}

identification of the most significant issues for the partner negotiation and selection processes. Based on UK industry, Goffin et al. (2007) produced empirical evidence for the today's move towards a reduction of the supplier base. More recently, Beil (2010) described the typical steps of a supplier selection process: identifying suppliers, soliciting information from suppliers, setting contract terms, negotiating with suppliers, and evaluating suppliers. Moreover, Beil highlighted also why each of these steps is important, how the steps are interrelated, and how the resulting complexity provides fertile ground for operations research and management science research.

\subsection{Quantitative Approaches}

\subsubsection{Non-Optimization Models}

Non-optimization models provide usually a ranking of the candidate suppliers based on a set of predefined selection criteria that address the necessary information for a buyer to make a decision. Non-optimization techniques include among others statistical and financial models, multicriteria techniques, and computer-based models.

One of the first approaches was that of Hinkle et al. (1969), who addressed the vendor evaluation problem using Cluster Analysis by considering the criteria of quality, delivery, net price, and technical capability, in a general industrial purchasing environment. Later on, Chapman and Carter (1990) addressed the supplier selection problem employing Multiple Regression Analysis, with an emphasis on manufacturing strategies such as just-in-time. Mummalaneni et al. (1996) presented the concept of Conjoint Analysis as a proper method for measuring preferences when six specific criteria (ontime delivery, quality, price/cost targets, professionalism, responsiveness to customer needs, and long-term relationships with the purchasing company) are used jointly in an overall evaluation. Petroni and Braglia (2000) presented an alternative multi-criteria decision-support model for evaluating the relative performance of suppliers based on the statistical multivariate Principal Component Analysis.

Ellram (1995) showed the linkage between Total Cost of Ownership (TCO) and supplier selection process, by highlighting the fact that purchasing costs is a crucial element of the total supply chain costs. Degreave et al. (2000) adopted the concept of TCO as a basis for comparing vendor selection models. They proved for a specific case study that, from a TCO perspective, mathematical programming models outperform rating models and multiple item models generate better results than single item one.

Nydick and Hill (1992) showed how Analytic Hierarchy Process (AHP) can be used to structure the supplier selection process and customized for the specific needs of each organization. Chen and Huang (2007) integrated AHP in a software agent technique, so as to take into account both qualitative and quantitative attributes in supplier selection. Morlacchi et al. (1997) used the Fuzzy Set Theory 
(FST) in order to develop a model that combines the use of fuzzy theory with AHP and implement it to evaluate small suppliers in the engineering and machine sectors. Weber and Desai (1996) demonstrated the use of Data Envelopment Analysis (DEA) for measuring vendor performance and efficiency, while they provided a methodology for the identification of benchmark values on a group of selected criteria for negotiating with inefficient vendors. Liu et al. (2000) presented a methodology of applying DEA to compare overall supplier performances and demonstrated the applicability of their model through a case study for a manufacturing firm. The objective of this DEA application is to aid decision-making for reducing the number of suppliers and to provide improvement targets for suppliers.

Vokurka et al. (1996) developed a prototype expert system (ES) for the evaluation and selection of potential suppliers that is adaptable to a variety of product considerations and types of business. In parallel, Cook (1997) described Case-Based Reasoning systems in purchasing. Moreover, Khoo et al. (1998) developed an Intelligent Software Agent that highlighted the use of information technologies on the supplier selection decision-making process. This technique includes a client agent from the computer of the sourcing organization, which visits the web sites of prospective vendors to determine if they can supply the desired products according to the procurement specifications. Jalao and Martinez (2009) systematized the supplier selection process for long-term purchasing with the use of a computerbased ES that mimics the purchasing decisions of a purchasing professional. The proposed expert system is called contract ES, and is composed of four functional modules: configuration, supplier evaluation, supplier selection and supplier performance monitoring. Celebi and Bayraktar (2008) presented a novel integration of Neural Network (NN) and DEA techniques for the evaluation of suppliers under incomplete information for the selection criteria. Finally, Temur et al. (2009) presented a study in order to give insights for the supplier assessment process by comparing $\mathrm{NN}$ and Discriminant Analysis methods, applied to real world data from 51 long term suppliers of a medium sized company from German Iron and Steel Industry. The criteria that they considered were the following: material quality, distance, discounts on amount and discounts on cash, annual revenue, payment terms, and delivery length.

\subsubsection{Optimization Models}

Optimization models minimize a cost objective function, as a rule, in order to assist decision-makers in finding the optimal solution for the investigated problem. These techniques include among others mixed integer-programming (MIP), multi-objective programming (MOP), goal-programming (GP), and simulation models.

Chaudhry et al. (1993) employed MIP techniques to address the problem of vendor selection in which a buyer must choose order quantities to place with vendors in a multiple-sourcing network. Furthermore, the authors take into account the price, delivery, and quality of the products, along with the capacity constraints of the vendors, while they assume that suppliers offer price discounts which depend on the size of the order quantities. Similarly, Rosenthal et al. (1995) developed a MIP model that provides the optimal purchasing strategy by minimizing the total purchase cost.

Weber and Current (1993) presented a MOP approach to systematically analyze the inherent tradeoffs involved in multi-criteria vendor selection problems. More recently, Amid et al. (2006) developed a fuzzy MOP model, assigning different weights to various criteria in order to overcome the vagueness of the information that arise in practice, regarding goals, constraints and parameters in the vendor selection problem.

Karpak et al. (1999) used visual interactive GP as a multi-criteria decision analysis tool in order to provide support to decision-makers to identify appropriate vendors and allocate purchase orders among them, while minimizing product acquisition costs and maximizing total product quality and delivery reliability. Kumar et al. (2003) formulate the vendor selection problem as a fuzzy mixed integer GP problem, including three primary goals: minimizing the net cost, minimizing the net rejections, and minimizing the net late deliveries subject to a set of realistic constraints (e.g. buyer's demand, vendors' capacity, vendors' quota flexibility, purchase value of items, budget allocation to individual vendors, etc.). 
In order to take into account the uncertainties in the supplier selection problem, Ding et al. (2006) presented a simulation methodology that is composed of three basic modules: a genetic algorithm optimizer, a discrete-event simulator and a supply chain modeling framework.

Hybrid models that combine two or more analytical techniques are also found in the literature. For instance, Ghoudsypour and O' Brien (1998) presented an integrated AHP and linear-programming (LP) capacitated (or not) model to consider both tangible and intangible factors in choosing the best suppliers and placing the optimum order quantities among them such that the total value of purchasing becomes maximum. Furthermore, $\mathrm{Wu}$ and Olson (2008) considered three types of vendor selection models: chance constrained-programming, DEA, and MOP, so as to provide alternative tools for the evaluation and improvement of the supplier selection decisions in an uncertain supply chain environment.

\subsection{Contribution}

The vast majority of the past research efforts focus solely on the selection phase of the overall procurement process. Thus, critical steps of this process such as the identification of the organization's needs, the definition of the procurement strategy, the incorporation of all the relevant in each case selection criteria into an optimization model, the periodic reevaluation of new potential suppliers for the scope of retaining or changing the selected ones, and the performance monitoring of the existing suppliers are partially considered and analyzed, and not in an integrated manner.

Our research work presents a holistic methodological framework for the optimization of the procurement process, including the development of a conceptual decision-making methodology that address the whole life cycle of the supplier selection and evaluation processes and a novel generic goalprogramming model for the initial selection and the periodic re-evaluation of vendors.

\section{A Supplier Selection Methodological Framework}

In this section a generic methodological framework for the supplier selection evaluation problem is presented (Figure 1). The proposed decision-making methodology is comprised of five main phases: the first three phases of the framework (I, II and III) deal with the initial supplier assessment and selection problem, while Phases IV and V are related to the continuous evaluation of the selected suppliers and the periodic re-evaluation of all the potential suppliers (new and old), for the scope of retaining or changing the selected ones.

In Phase I an organization has to firstly identify its procurement needs/requirements and subsequently the procurement strategy that will be followed. Then, Phase II of the framework deals with the identification of the potential suppliers. The determination of the alternative information sources of suppliers is a key driver of the success or failure of the whole process from a performance perspective. Online searches, companies' web sites, advertisements, trade shows, and professional contacts are the most common tools used today.

After developing a comprehensive list of potential suppliers, the next step is to evaluate each prospective supplier and select the suppliers with whom the organization will initially co-operate (Phase III). First of all, the selection criteria have to be defined, which is generally a case specific process mainly depending on the procurement strategy and the particular needs of each company (Guneri and Kuzu, 2008). Following, specific goals along with their target values that need to be achieved during the procurement process have to be clearly stated. These goals will derive from the selection criteria. Next, companies should collect the required data for each potential supplier, in order to initiate the evaluation process. The next step of Phase III, concerns the optimization of the supplier selection process through an analytical model that should take into account explicitly all the potential suppliers and the goals set by the buyer. The solution of this model will lead to the selection of the best $n$ desired suppliers. One of the $n$ selected vendors will play the role of the key supplier, while the rest secondary ones have to be classified according to their characteristics. To this effect, visits to the $n$ suppliers' facilities can be conducted, so as the buyer can obtain firsthand information about their capabilities.

Following the selection of the vendor partners for the first period of the planning horizon, organizations should proceed to Phase IV of the framework, which concerns the continuous 
Figure 1. The proposed five-phased methodological framework

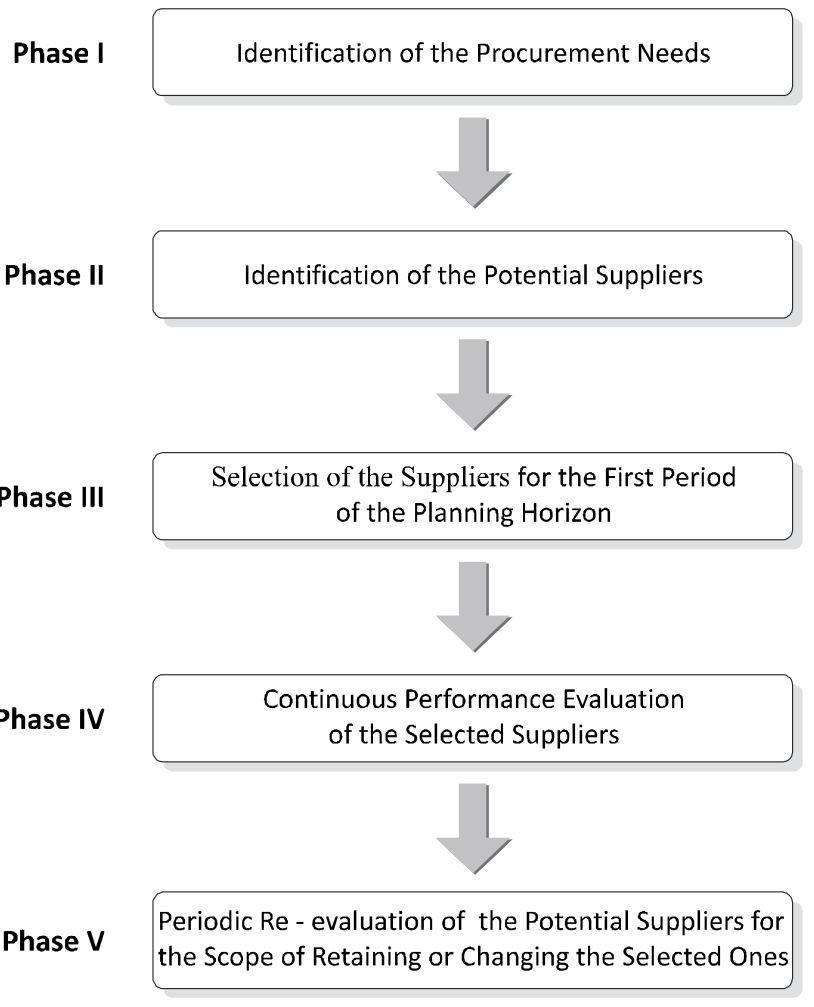

performance monitoring of the selected suppliers. The first step in Phase IV is the development of companyspecific supplier measurement indicators, through which the performance of the suppliers will be continuously evaluated. After that the organizations can assess the performance of the selected suppliers through the establishment of proper statistical quality control techniques. In specific cases where an organization confronts poor performance with some of the selected suppliers, it should proceed as soon as possible to the evaluation of the new potential suppliers that will substitute the selected ones.

Finally, Phase $\mathrm{V}$ of the methodological framework deals with the re-evaluation of all the potential suppliers for the scope of retaining or changing the selected ones. In order to have a change in the supplier base, the expected performance of the new potential suppliers that compete with the existing ones should be better than that of them. Re-evaluation is a periodic process accomplished in predetermined time intervals. The first step of Phase V is the assessment of the selected suppliers based on the output data of Phase IV. If the performance of the selected suppliers is fully satisfactory then the organization should continue monitoring them according to Phase IV and not proceed with Phase V, else it has to carry on with the next steps of Phase $V$ that are similar to those described for Phases II and III.

\section{Formulation of a Multi-Criteria Supplier Selection Model}

The type of evaluation required to optimize supplier selection varies with the nature, criticality, and monetary value of the purchase to be made and thus it is not possible to specifically model a single functional formulation that will address all the problem settings. Consequently, we present a generic formulation of the investigated problem for a single item that is purchased from $n$ vendors. Furthermore, the demand of the item is supposed to be forecasted with a relatively good accuracy, while there is a restriction to the total purchasing budget allocated to this product.

Based on our experience on the procurement management and on the literature review presented in Section 2, we propose an integrated set of selection criteria, which correspond to specific hierarchically categorized goals. Specifically, we have taken into account three priority levels in which all the considered goals are properly allocated. Tables 2, 3, and 4 present the goals of the first, second and third priority level in alphabetical order. We denote with $T_{j}^{i}$ the $j^{\text {th }}$ goal/target of the $i^{\text {th }}$ priority. All the goals can have a ranking range following the Likert scale from 1 (less desired value) to 5 (most desired value).

The next step is to present the proposed generic goal-programming model for the optimization of the supplier selection process, corresponding to Phases

Table 2. First priority goals and selection criteria

\begin{tabular}{|l|}
\hline Goals \\
\hline$T_{1}^{1}:$ Financial terms of agreement \\
\hline$T_{2}^{1}:$ Lead time \\
\hline$T_{3}^{1}:$ Maximum order quantities \\
\hline$T_{4}^{1}:$ Purchase price \\
\hline$T_{5}^{1}:$ Quality of products \\
\hline
\end{tabular}


Table 3. Second priority goals and selection criteria

\begin{tabular}{|l|}
\hline Goals \\
\hline$T_{1}^{2}:$ Customer service \\
\hline$T_{2}^{2}:$ Geographical proximity \\
\hline$T_{3}^{2}:$ Logistics performance \\
\hline$T_{4}^{2}:$ Position in industry \\
\hline$T_{5}^{2}:$ Reputation \\
\hline$T_{6}^{2}:$ Risk-management issues \\
\hline$T_{7}^{2}:$ Long-term relationship \\
\hline
\end{tabular}

III and V of the proposed decision-making methodological framework. We adopt the minimum maximization formulation for goal-programming in which the maximum deviation from any goal is minimized. The solution of this model will identify the best $n$ desired vendors. One of these vendors will be the key supplier from which the buyer will satisfy the largest possible part of his/her needs for the investigating item, while the rest quantity will be met by the secondary suppliers.

Table 4. Third priority goals and selection criteria

\begin{tabular}{|l|}
\hline Goals \\
\hline $\mathrm{T}_{1}^{3}:$ Continuous improvement \\
\hline $\mathrm{T}_{2}^{3}:$ Co-operation with competitors \\
\hline $\mathrm{T}_{3}^{3}:$ E-commerce \\
\hline $\mathrm{T}_{4}^{3}:$ Environmental orientation \\
\hline $\mathrm{T}_{5}^{3}:$ Facilities \\
\hline $\mathrm{T}_{6}^{3}:$ Insurance \& warranty policies \\
\hline $\mathrm{T}_{7}^{3}:$ Research \& development \\
\hline
\end{tabular}

The following notations were used for the variables and parameters of the model: $s \in 1 \ldots S$ is the set of all the potential suppliers; $u_{i j}^{-}$and $u_{i j}^{+}$ represent generally the deviational variables from each goal $j$ and for each priority level $i$; $D$ is the variable that denotes the maximum deviation from all the considered goals; $Y_{s}$ is a binary variable that indicate whether supplier $s$ will be selected or not; $B$ is the budget allocated to the examined item over a fixed planning period; $C_{s}$ is the capacity of supplier $s$ over a fixed planning period; $Q$ is the forecasted aggregate demand of the item over a fixed planning period; $s f$ is a security factor for the forecasted demand; $n$ is the number of vendors competing for selection; $v_{s}$ is the unit purchase price of the item ordered from supplier $s ; r_{i j}^{s}$ is the rating of supplier $s$ for the $j^{\text {th }}$ goal of the $i^{\text {th }}$ priority level; $z_{1}$ and $z_{2}$ are coefficients with a domain from 0 to 1 (with $z_{1}<z_{2}$ ) that reduce the maximum acceptable deviation from all the considered goals of the first and the second priority level, respectively, in relation to the maximum deviation from the goals of the third priority.

The proposed supplier selection optimization model is formulated as follows:

\section{- Objective function:}

Minimize D

\section{- Subject to:}

(1) $\sum_{s=1}^{S} Y_{s} \leq n$

(2) $Q \cdot \sum_{s=1}^{S}\left(v_{s} \cdot Y_{s}\right)-B \cdot \sum_{s=1}^{S} Y_{s} \leq 0$

(3) $\sum_{s=1}^{S}\left(C_{s} \cdot Y_{s}\right) \geq s f \cdot Q$

(4) $\sum_{s=1}^{S}\left(r_{i j}^{s} \cdot Y_{s}\right)-T_{j}^{i} \cdot \sum_{s=1}^{S} Y_{s}+u_{i j}^{-} \geq 0, \forall i$,

$j$ except for $i=1$ and $j=2,4$ and 5

(5) $\sum_{s=1}^{S}\left(r_{i j}^{s} \cdot Y_{s}\right)-T_{j}^{i} \cdot \sum_{s=1}^{S} Y_{s}-u_{i j}^{+} \leq 0$,

for $i=1$ and $j=2,4$ and 5

(6) $u_{i j}^{-} / T_{j}^{i} \leq z_{1} D$, for $i=1$ and $j=1,3$ and 6

(7) $u_{i j}^{+} / T_{j}^{i} \leq z_{1} D$, for $i=1$ and $j=2,4$ and 5

(8) $u_{i j}^{-} / T_{j}^{i} \leq z_{2} D$, for $i=2$ and $\forall j$ 


$$
u_{i j}^{-} / T_{j}^{i} \leq D \text {, for } i=3 \text { and } \forall j
$$

$$
Y_{s} \text { are binary variables, while } D, u_{i j}^{+} \text {and } u_{i j}^{-} \in_{i}^{+}
$$

The objective function allows us to minimize the maximum deviation from all the goals. On the other hand, appropriate hard and soft constraints are developed. The first three constraints are the hard ones with constraint (1) establishing the maximum number of vendors to be selected. Inequality (2) denotes that the budget allocated to the item over the planning period should not be exceeded. Constraint (3) ensures that the maximum possible quantity that can be ordered for the item from all the selected vendors is at least equal with the forecasted demand over the planning horizon augmented by the case-specific security factor $s f$. Inequalities (4) and (5) are the classical soft constraints with the deviational variables included. Inequalities (6) to (9) indicate that all the percentage deviations from the various goals will not exceed the value of $D$. Constraint sets (10) reflect the binary nature of the vendor selection decision, and the fact that the all the other variables employed are continuous and non-negative.

\section{Conclusions and Discussion}

In this paper we propose a multi-criteria decisionsupport methodological framework for the optimization of the supplier selection and evaluation problem, along with a goal-programming model and a set of newly-defined qualitative criteria/goals for capturing a number of real-world issues. The proposed analytical model is quite generic since it is not possible to specifically model a single functional formulation for all the business environments.

The current work can be extended in order to incorporate the allocation of purchase quantities among the selected suppliers and the consideration of the multiple-item problem. A further issue that is worth exploring is that of supplier performance monitoring. Finally, few additional aspects that we intend to take into account in the near future are the ranking of the suppliers through a new optimization model and stochasticity of the quality of the products.

\section{References}

Amid, S., Ghodsypour, H., and O’Brien, C. (2006), Fuzzy Multi-objective Linear Model for Supplier Selection in a Supply Chain. Production Economics 104, pp. 394-407.

Beil, R.D. (2010), Supplier Selection. Wiley Encyclopedia of Operations Research and Management Science. John Wiley \& Sons.

Çelebi, D., and Bayraktar, D. (2008), An integrated neural network and data envelopment analysis for supplier evaluation under incomplete information. Expert Systems with Applications 35 (4), pp. 1698-1710.

Chapman, S.N., and Carter, P.L. (1990), Supplier/customer inventory relationships under just in time. Decision Sciences 21, pp. 35-51.

Chaudhry, S.S., Forst, F.G. and Zydiak, J.L. (1993), Vendor selection with price breaks. European Journal of Operational Research 70, pp. 52-66.

Chen, Y.M., and Huang, P.N. (2007). Bi-negotiation integrated AHP in suppliers selection. Benchmarking: An International Journal 14 (5), pp. 575-593.

Cook, R.L. (1997), Case-based reasoning systems in purchasing: applications and development. International Journal of Purchasing and Materials Management 33 (1), pp. 32-39.

De Boer, L., van Dijkhuizen, G., and Telgen, J. (2000), A basic for modeling the cost of supplier selection: the economic tender quantity. Journal of the Operation Research Society 51, pp. 1128-1135.

Degraeve, Z., Labro, E. and Roodhooft, F. (2000), An evaluation of vendor selection models from a total cost of ownership perspective. European Journal of Operational Research 125, pp. 34-58.

Dempsey, W.A. (1978), Vendor selection and the buying process. Industrial Marketing Management 7, pp. 257267.

Dickson, G.W. (1966), An analysis of vendor selection systems and decisions. Journal of Purchasing 2 (1), pp. 5-17.

Ding, H., Benyoucef, L. and Xie, X. (2006), A simulationbased multi-objective genetic algorithm approach for networked enterprises optimization. Engineering Applications of Artificial Intelligence 19 (6), pp. 609-623.

Ellram, L.M. (1995), Total cost of ownership: An analysis approach for purchasing. International Journal of Physical Distribution and Logistics 25 (8), pp. 4-23.

Ghoudsypour, S.H., and O'Brien, C.O. (1998), A decisionsupport system for supplier selection using an integrated analytic hierarchy process and linearprogramming. International Journal of Production Economics 56-57 (1-3), pp. 199-212. 
Goffin, K., Szwejczewski, M., New, C. (1997), Managing suppliers: when fewer can mean more. International Journal of Physical Distribution \& Logistics Management 27 (7), pp. 422-436.

Guneri, A.F., and Kuzu, A. (2008), Supplier selection by using a fuzzy approach in just-in-time: a case study. International Journal of Computer Integrated Manufacturing 22 (8), pp. 774-783.

Hakansson, H., and Wootz, B. (1975), Supplier selection in an international environment - An experimental study. Journal of Marketing Research XII, pp. 46-51.

Hinkle, C.L., Robinson, P.J., and Green, P.E. (1969). Vendor evaluation using cluster analysis. Journal of Purchasing, pp. 49-58.

Ho, W., Xu, X., and Dey, P.K. (2010), Multi-criteria decision-making approaches for supplier evaluation and selection: A literature review. European Journal of Operational Research 202 (1), pp. 16-24.

Jalao, E.R.L., and Martinez, I.A.G. (2009), The Contract Expert System: A Proposal for Long-Term Supplier Evaluation, Selection and Performance Monitoring. Proceedings of the International MultiConference of Engineers and Computer Scientists 2009 Vol. I (IMECS 2009), March 18-20, Hong Kong.

Karpak, B., Kasuganti, R.R. and Kumcu, E. (1999), Multiobjective decision-making in supplier selection: an application of visual interactive goal-programming. The Journal of Applied Business Research 15 (2), pp. 5771.

Khoo, L.P., Tor, S.B., and Lee, S.S.G. (1998), The potential of intelligent software agents in the World Wide Web in the automated part procurement. International Journal of Purchasing and Materials Management 34 (1), pp. 46-52.

Kumar, M., Vrat, P. and Shankar, R. (2003), A fuzzy goalprogramming approach for vendor selection problem in a supply chain. Computers $\mathcal{E}$ Industry Engineering 46 , pp. 69-85.

Lewis, H. (1943), Industrial Purchasing Principles and practices. Chicago: Richard Erwin.

Liu, J., Ding, F.Y., and Lall, V. (2000), Using Data Envelopment Analysis to compare suppliers for supplier selection and performance improvement. Supply Chain Management: An International Journal 5 (3), pp. 143-150.

Masella, C., Rangone, A. (2000), A contingent approach to the design of vendor selection systems for different types of cooperative customer/supplier relationships. International Journal of Operations and Production Management 20 (1), pp. 70-84.
Morlacchi, P., Pavesi, S., and Savoldelli, A. (1997), Sourcing relationships within the supply chain of Italian machinery sector: supplier selection as a first step to manage supply chain. Proceedings of IFIPWG 5.7 Conference, $15^{\text {th }}-18^{\text {th }}$ September, Ascona, Switzerland.

Mummalaneni, V., Dubas, K.M., and Chao, C.N. (1996), Chinese Purchasing Managers' Preferences and Tradeoffs in Supplier Selection and Performance Evaluation. Industry Marketing Management 25, pp. 115-124.

Nydick, R.L., and Hill, R.P. (1992), Using the Analytic Hierarchy Process to structure the supplier selection procedure. International Journal of Purchasing and Materials Management 28 (2), 31-36.

Petroni, A., and Braglia, M. (2000), Vendor selection using principal component analysis. The Journal of Supply Chain Management: A Global Review of Purchasing and Supply 36 (2), pp. 63-69.

Pidduck, A.B. (2006), Issues in supplier partner selection. Journal of Enterprise Information Management 19 (3), pp. 262-276.

Rosenthal, E.C., Zydiak, J.L. and Chaudhry, S. S. (1995), Vendor selection with bundling. Decision Science 26 (1), pp. 35-48.

Spekman, R.E. (1988), Strategic Supplier Selection: Understanding Long-Term Buyer Relationships. Business Horizons 31 (4), pp. 75-81.

Temur, G.T., Ozdemir, D., and Kaya, T. (2009), Supplier evaluation system development with artificial neural network and discriminant analysis: a comparative study. European and Mediterranean Conference on Information Systems 2009 (EMCIS2009), July 13-14 2009, Izmir.

Vokurka, R.J., Choobineh, J., and Vadi, L. (1996), A prototype expert system for the evaluation and selection of potential suppliers. International Journal of Operations and Production Management 16 (12), pp. 106127.

Weber, C.A. and Current, J.R. (1993), A multiobjective approach to vendor selection. European Journal of Operational Research 68, pp. 173-184.

Weber, C.A., Current, J.R. and Benton, W.C. (1991), Vendor selection criteria and methods. European Journal of Operational Research 50, pp. 2-18.

Weber, C.A., and Desai, A. (1996), Determination of paths to vendor market efficiency using parallel co-ordinates representation: a negotiation tool for buyers. European Journal of Operational Research 90, pp. 142-155.

Wu, D. and Olson, D.L., (2008), Supply chain risk, simulation and vendor selection. International Journal of Production Economics 114 (2), pp. 646-655. 
Mr. Christos Keramydas is a PhD candidate and a member of the Laboratory of Quantitative Analysis, Logistics and Supply Chain Management, Department of Industrial Management, Mechanical Engineering School, Aristotle University of Thessaloniki (AUTh), Greece. He also holds a Master of Science in Statistics and Modelling from the School of Sciences (Department of Mathematics) of the AUTh. His research interests, as well as his teaching experience (teaching assistant), are spread in the fields of Statistics, Operations Research, Simulation applications and Forecasting. More specifically, these interests include supply chain management, logistics, and simulation applications for addressing issues and problems pertaining to container terminals, healthcare systems, suppliers, and more recently green logistics. He has published articles in several scientific journals, and national/international conferences' proceedings. He is a member of the Greek Society of Logistics Engineers.

Dr. Anastasios Xanthopoulos is an elected Lecturer at the Mechanical Engineering Department/Industrial Management Division of the Aristotle University of Thessaloniki (AUTh), Greece. Dr. Xanthopoulos received his Diploma in Mechanical Engineering with Honors in 2003, and his Ph.D., both at the Department of Mechanical Engineering of AUTh. He is a Researcher in the fields of Production Systems and Applied Operations Research, and his work deals mainly with Supply Chain and Inventory Management, and Reverse Logistics. He has already published his work in a considerable number of Logistics and Supply Chain Management oriented international scientific journals, such as the International Journal of Logistics Systems and Management, International Journal of Logistics Economics and Globalization etc., as well as in relevant book chapters, and conferences' proceedings.

Dr. Dimitrios Aidonis is Lecturer at the Department of Standardization and Transportation (Logistics) of the Alexander Technological Educational Institute of Thessaloniki, Greece. He received both his Diploma in Mechanical Engineering and a Ph.D. from the Department of Mechanical Engineering of Aristotle University of Thessaloniki and his MBA from Staffordshire University, UK. He is a researcher in the fields of Applied Operations Research, and his work deals mainly with Supply Chain and Reverse Logistics Management. He has published articles in several scientific journals and international conferences' proceedings. He is a member of the Society of Logistics Engineers, CSCMP, and the Technical Chamber of Greece. 